\title{
Development of a screening approach for exploring cell factory potential through metabolic flux analysis and physiology
}

\author{
Knudsen, Peter Boldsen; Nielsen, Kristian Fog; Thykær, Jette
}

Published in:

New Biotechnology

Link to article, DOI:

10.1016/j.nbt.2012.08.594

Publication date:

2012

Document Version

Publisher's PDF, also known as Version of record

Link back to DTU Orbit

Citation (APA):

Knudsen, P. B., Nielsen, K. F., \& Thykær, J. (2012). Development of a screening approach for exploring cell factory potential through metabolic flux analysis and physiology. New Biotechnology, S212.

https://doi.org/10.1016/j.nbt.2012.08.594

\section{General rights}

Copyright and moral rights for the publications made accessible in the public portal are retained by the authors and/or other copyright owners and it is a condition of accessing publications that users recognise and abide by the legal requirements associated with these rights.

- Users may download and print one copy of any publication from the public portal for the purpose of private study or research.

- You may not further distribute the material or use it for any profit-making activity or commercial gain

- You may freely distribute the URL identifying the publication in the public portal 


\section{Poster 5.0.154}

Development of a screening approach for exploring cell factory potential through metabolic flux analysis and physiology

Peter Boldsen Knudsen*, Kristian Fog Nielsen, Jette Thykaer

Center for Microbial Biotechnology, Department of Systems Biology, Technical University of Denmark, Kgs Lyngby, Denmark

The recent developments within the field of metabolic engineering have significantly increased the speed by which fungal recombinant strains are being constructed, pushing focus towards physiological characterisation and analysis. This raises demand for a tool for diligent analysis of the recombinant strains in order to evaluate their potential as fungal cell factories and for guiding further metabolic engineering strategies. To meet the demand for a fast and reliable method for physiological characterisation of fungal strains, a screening approach using a micro titer format was developed on a Hamilton robotic system. This method aimed at characterising physiology at two levels:

(1) An approach focusing on the traditional growth related parameters, i.e. growth rate, yield coefficients and extracellular metabolites.

(2) ${ }^{13} \mathrm{C}$-labelling experiments, where metabolic fluxes are quantified in the strains of interest during exponential growth.

The novelty of this screening approach, is that potential cell factories are selected based on their metabolic capacity for producing various products on interest and these cell factories may in turn be characterised based on their flux distributions. As part of the validation, already well described fungal strains were selected and tested using the described method and the developed method was subsequently used to test recombinant fungal strains producing the model polyketide 6-methylsalicylic acid.

Diligent application of this strategy significantly reduces the cost and work-load connected with screening and selection of potential cell factories with attractive properties, compared with more "traditional" methodologies where metabolic flux analysis is applied at a much later state in the characterisation process.

http://dx.doi.org/10.1016/j.nbt.2012.08.594

Poster 5.0.155

\section{Physiological characterisation of Yarrowia lipolytica} yields new features of the strain

Philippe Holt*, Jette Thykaer, Mhairi M. Workman

Department of systems biology, Technical University of Denmark, Denmark

Yarrowia lipolytica is a potential candidate for the production of value-added compounds from glycerol. Products include citric acid as well as those of the group known as polyols with significant industrial relevance.

In this study the yeast is taken back to a more thorough physiological characterisation in submerged cultures, providing the basis for the formulation of an initial model for the glycerol and glucose metabolism.
The strain has been cultivated on glycerol and glucose and a combination of both, this approach has shown that the strain, unlike $S$. cerevisae, favors glycerol as a substrate over glucose when both are present in a liquid culture. Glycerol is initially utilised via an oxygen dependent pathway, and latter by an oxygen independent pathway, while glucose is utilised latter by aerobic metabolism. Even though the two substrates are metabolised differently, and each of the phases can be clearly distinguished in submerged cultivation, no diauxic growth curve is observed. The maximal specific growth rate on dual substrates is significantly higher than the growth rate on glucose, leading to the hypothesis that the availability of glycerol is boosting the metabolism of glucose.

Data also suggest multiple entries to pathways responsible for polyol production as these are produced both during the metabolism of dual substrates and during the metabolism solely of glycerol. Based on analysis of off-gas data and secreted products, metabolic pathways are suggested for the production polyols.

http://dx.doi.org/10.1016/j.nbt.2012.08.595

\section{Poster 5.0.156}

\section{Structure and function of swine fever virus N-terminal autoprotease}

Schindler Sabrina ${ }^{1, *}$, Sponring Michael $^{1}$, Zoegg Thomas ${ }^{2}$, Koll Maria $^{1}$, Brandstetter Hans ${ }^{2}$, Schneider Rainer ${ }^{1}$, Auer Bernhard ${ }^{1}$

${ }^{1}$ Austrian Centre of Industrial Biotechnology (ACIB) c/o Institute of Biochemistry, University of Innsbruck, Innrain 80/82, 6020 Innsbruck, Austria

${ }^{2}$ Structural Biology Group, Research Centre of Biosciences and Health, University of Salzburg, Billrothstraße 11, 5020 Salzburg, Austria

$\mathrm{N}$-terminal autoprotease $\mathrm{N}^{\text {pro }}$ of Classical Swine Fever Virus can be used as a tool for expression of recombinant proteins in E. coli. Due to its autocatalytic cleavage it enables synthesis of proteins with an authentic N-terminus, which is especially important for pharmaceutical applications. Furthermore, small peptides can be stably expressed in E. coli by linking them C-terminally to $\mathrm{N}^{\text {pro }}$. A high expression rate forces the fusion protein into inclusion bodies. After purification, $\mathrm{N}^{\text {pro }}$ is refolded and cleaves itself off. $\mathrm{N}^{\text {pro }}$ is relatively insoluble and aggregates easily. Hence, different $\mathrm{N}^{\text {pro }}$ variants were isolated and examined for their solubility and cleavage rate in combination with different fusion partners [1].

Here we present the $3 \mathrm{D}$ structure of $\mathrm{N}^{\text {pro }}$ at $1.5 \AA$ resolution. The overall structure appears to be quite globular and rather compact in spite of very few secondary structural elements. A catalytic dyad of H49 and C69 is very likely. This atypical arrangement is the basis to assign $\mathrm{N}^{\text {pro }}$ to a new subfamily of cysteine proteases, C53.

After cleavage autoprotease $\mathrm{N}^{\text {pro }}$ carries out an additional task in vivo as it interferes with the cellular interferon system. A proposed zinc-binding motif consisting of three cysteine and one aspartate residue is considered to be essential for interaction with Interferon Regulatory Factor 3 (IRF 3) and targeting IRF 3 to the proteasome. 